\title{
Prevalence and clinical features of COVID-19 in a large cohort of 199 patients with sarcoidosis
}

\section{Anne-Claire Desbois}

Hopital Universitaire Pitie Salpetriere

Cindy Marques ( $\nabla$ cindymarques@ymail.com )

Hopital Universitaire Pitie Salpetriere https://orcid.org/0000-0002-1361-0575

\section{Leila Lefèvre}

Hopital Universitaire Pitie Salpetriere

\section{Serge Barmo}

Hopital Universitaire Pitie Salpetriere

\section{Camille Lorenzo}

Hopital Universitaire Pitie Salpetriere

Mathilde Leclercq

Hopital Universitaire Pitie Salpetriere

\section{Gaëlle Leroux}

Hopital Universitaire Pitie Salpetriere

Chloé Comarmond

Hopital Universitaire Pitie Salpetriere

Catherine Chapelon

Hopital Universitaire Pitie Salpetriere

Fanny Domont

Hopital Universitaire Pitie Salpetriere

\section{Mathieu Vautier}

Hopital Universitaire Pitie Salpetriere

\section{David Saadoun}

Hopital Universitaire Pitie Salpetriere

\section{Patrice Cacoub}

Hopital Universitaire Pitie Salpetriere

\section{Research article}

Keywords: sarcoidosis, COVID-19, SARS-CoV-2

Posted Date: July 20th, 2020 
DOI: https://doi.org/10.21203/rs.3.rs-41653/v1

License: (c) (1) This work is licensed under a Creative Commons Attribution 4.0 International License. Read Full License

Version of Record: A version of this preprint was published at Clinical and Experimental Rheumatology on January 28th, 2022. See the published version at https://doi.org/10.55563/clinexprheumatol/b7zd6b. 


\section{Prevalence and clinical features of COVID-19 in a large cohort of 199 patients with}

2 sarcoidosis

3 Anne-Claire Desbois* ${ }^{* 1,2,3}$, Cindy Marques*1,2,3 Leila Lefèvre $^{2,3}$, Serge Barmo ${ }^{2,3}$, Camille

4 Lorenzo $^{2,3}$, Mathilde Leclercq ${ }^{2,3}$, Gaëlle Leroux ${ }^{2,3}$, Chloé Comarmond ${ }^{1,2,3}$, Catherine

5 Chapelon-Abric ${ }^{2,3}$, Fanny Domont ${ }^{2,3}$, Mathieu Vauthier ${ }^{2,3}$, David Saadoun ${ }^{1,2,3}$, Patrice

6 Cacoub $^{1,2,3}$

7 * equal contribution

8

9 1. Sorbonne Universités, UPMC Univ Paris 06, INSERM, UMR S 959, Immunology-

10 Immunopathology- Immunotherapy (I3); F-75005, Paris, France;

11 2. Biotherapy (CIC-BTi) and Inflammation-Immunopathology-Biotherapy Department (DHU

12 i2B), Hôpital Pitié-Salpêtrière, AP-HP, F-75651, Paris, France;

13 3. AP-HP, Groupe Hospitalier Pitié-Salpêtrière, Department of Internal Medicine and Clinical

14 Immunology, F-75013, Paris, France, Centre national de référence des Maladies

15 Autoimmunes et systémiques rares et Maladies Autoinflammatoires rares

16

17 Correspondence: Anne-Claire Desbois, MD, PhD, Department of Internal Medicine and

18 Clinical Immunology, Hôpital Pitié-Salpêtrière, 47-83 boulevard de l'Hôpital, 75013 Paris.

19 Phone: + (33)(1) 421780 68. Fax: + (33)(1) 42178033.

20 E Mail:anneclaire.desbois@aphp.fr

21

22 Conflict of interest: The authors have declared that no conflict of interest exists. 23

24 Word Count: 1496 words, 10217 characters (including spaces), 2 tables, 20 references. 


\section{Funding:}

42 The authors declare that they have no source of funding.

\section{Ethics approval and consent to participate:} research in Sorbonne University". All patients gave informed consent.

\section{Consent for publication:}

Not applicable.

Availability of data and materials: corresponding author on reasonable request.

\section{Competing interests:}

The authors declare that they have no competing interests.

Authors' contributions:

ACD contributed to the conception and design of the work.

ACD and CM wrote the manuscript.

CM have drafted the work

PC supervised the findings of this work.

All authors approved the final manuscript.

\section{Acknowledgements:}

The study was approved by our institutional ethics review board "Ethics committee of

The datasets used and/or analyzed during the current study are available from the

ACD, CM, LL, SB, CL, ML, GL, CC, CCA, FD, MV and DS collected the data.

We thank all patients and all physicians involved in the care of the patients. 


\section{Abstract}

55 Objective: To investigate the prevalence, clinical features and outcomes of coronavirus disease 2019 (COVID-19) among sarcoidosis patients.

57 Methods: We retrospectively collected features of COVID-19 in a cohort of patients with sarcoidosis followed in a single tertiary university hospital.

59 Results: Among 199 sarcoidosis patients [mean age $58.8( \pm 14)$ years, $86(43.2 \%)$ men], 26 $60(13 \%)$ were diagnosed with COVID-19 [definite $(n=7)$, probable $(n=12)$ and possible $(n=7)$ ]. 61 Twenty-four out of 26 patients (92\%) had at least one comorbidity, and 11/26 (42\%) had two 62 or more comorbidities. Demographic and clinical features of COVID-19 positive patients were similar to those of COVID-19 negative patients. The administration of hydroxychloroquine or immunosuppressant was not associated with the occurrence or the severity of COVID-19. Four out of 26 (15.4\%) COVID-19 positive patients required admission to hospital and two of them died. Hospitalized patients [mean age of $61( \pm 11.5)$ years] were receiving higher doses of long term treatment with corticosteroids than nonhospitalized patients; 4/4 had pulmonary and 2/4 cardiac involvement of sarcoidosis, and all one or more comorbidity.

Conclusion: The prevalence of COVID-19 in sarcoidosis is slightly higher to that of the general population. Almost half of the COVID-19 positive patients have two or more comorbidities and about $15 \%$ present a severe course.

74 Word count: 200 words.

75

76 Keywords: sarcoidosis; COVID-19; SARS-CoV-2 
79 List of abbreviations:

80 ACE: angiotensin-converting enzyme,

81 ARB: angiotensin II receptor blocker,

82 ARDS: severe acute respiratory syndrome,

83 COVID-19: coronavirus disease 2019,

84 ECMO: extracorporeal membrane oxygenation

85 IL6: interleukin 6,

86 NSAID: nonsteroidal anti-inflammatory drug,

87 SARS-CoV-2: severe acute respiratory syndrome coronavirus 2,

88 SD: standard deviation,

89 TNF: tumor necrosis factor.

91 Key messages:

92 What is already known about this subject?

93 Since the outbreak of COVID-19, many data have been published in the general population

94 and in some disease-specific groups, but data are lacking for patients with sarcoidosis.

95

96 What does this study add?

97 We reported the prevalence, clinical features and outcomes of COVID-19 in a cohort of 199

98 patients with sarcoidosis followed in a single French tertiary university hospital. The rate of

99 COVID-19 infections among patients with sarcoidosis appears to be very slightly higher to

100 that of the general population. The rates of hospitalization and mortality appeared to be higher

101 than in the general population.

102

103 How might this impact on clinical practice or future developments?

104 Cardiovascular comorbidities that are highly found in sarcoidosis patients probably make 105 them more vulnerable to severe COVID-19. These findings should lead to be cautious for 106 management of sarcoidosis patients during the pandemic. 
108 Coronavirus disease 2019 (COVID-19), mediated by SARS-CoV-2 (severe acute respiratory syndrome coronavirus 2) is responsible for a major health crisis worldwide. COVID-19 can

110 be complicated with a severe acute respiratory syndrome (ARDS) and multi-organ failure.

111 Sarcoidosis is a granulomatous disease of unknown origin affecting the lungs, the lymphatic

112 nodes but also the nervous system, the eyes and the heart. The reported incidence among

113 African and Americans in the United States is 35.5/100,000 compared with 10.9/100,000 in

114 Caucasian patients (1). The incidence and the severity of COVID-19 in patients with 115 sarcoidosis remains an unsolved issue. Sarcoidosis can be complicated by interstitial 116 pneumonia leading to severe pulmonary illness. Immunosuppressive drugs are often used 117 making sarcoidosis patients more vulnerable to infections. COVID-19 can be responsible for a 118 cytokine storm syndrome for which immunosuppressive strategy could be beneficial $(2,3)$. 119 To date, there is no data on clinical features of COVID-19 in sarcoidosis patients. A recent 120 comparative cohort study showed that patients with rheumatic disease and COVID-19 121 infection were more likely to require mechanical ventilation but had similar mortality and 122 hospitalization rates compared to patients without rheumatic disease (4).

\section{Methods}

125 This study was performed at the Department of Internal Medicine and Clinical Immunology 126 in the tertiary university hospital Pitié-Salpêtrière (Paris, France). This study was approved by 127 the local Ethic Committee. All patients with sarcoidosis, followed at the department were 128 included. From May, $1^{\text {st }} 2020$ to $27^{\text {Th }}$ May, six weeks after the pandemic peak in France, we systematically contacted by telephone patients followed in our center for sarcoidosis. We investigated their demographic characteristics, disease manifestations of sarcoidosis, the

131 presence of symptoms suggesting SARS-CoV-2 infection, the results of nasopharyngeal PCR

132 if available and their treatments. A definite COVID-19 was defined by the presence of 133 symptoms suggesting SARS-CoV-2 infection with positive nasopharyngeal PCR or serology. 134 A probable COVID-19 was defined by the presence of fever and/or three or more symptoms 135 suggesting SARS-CoV-2 infection associated with a contact with a person infected by SARS-

136 CoV-2 without available nasopharyngeal PCR. A possible COVID-19 was defined by the 137 presence of three symptoms or more suggesting SARS-CoV-2 infection without available 138 nasopharyngeal PCR and without history of contact with infected people.

139 Continuous variables are presented as mean $( \pm \mathrm{SD})$ and categorical variables as number $(\%)$.

140 Statistical comparisons were performed by using the Mann-Whitney test for quantitative 
141 unpaired data, and the Chi-Square test for categorical variables. All statistical tests were two-

142 tailed with a significance level of 0.05. Statistical significance was evaluated using GraphPad

143 Prism version 5.00 for Windows (GraphPad Software, San Diego, CA, USA).

144

\section{Results}

146 One hundred and nighty-nine patients diagnosed with sarcoidosis according to the criteria of

147 the latest American Thoracic Society/European Respiratory Society/World Association of

148 Sarcoidosis and Other Granulomatous Disorders statement on sarcoidosis (5) were included.

149 The mean age of patients was $58.8( \pm 14)$ years and $86(43.2 \%)$ were male. Among the cohort, $15026(13 \%)$ patients were diagnosed with COVID-19 [definite $(n=7)$, probable $(n=12)$ and 151 possible $(\mathrm{n}=7)]$.

152 COVID-19 positive sarcoidosis patients

153 Patients with COVID-19 consisted of $13(50 \%)$ men with a mean age of $50.3( \pm 13.6)$ years.

154 Main features of sarcoidosis included involvement of lungs (73\%), lymph nodes (50\%), heart 155 (15.4\%), central nervous system (23.1\%) and eyes (46.2\%). Twenty-four (92\%) patients had 156 at least one comorbidity [hypertension (26.9\%), diabetes (23.1\%), heart failure (7.7\%), 157 coronary artery disease (7.7\%), chronic obstructive lung disease/asthma (19\%), overweight $158(65.4 \%)$ or malignant tumors (3.8\%)]. Eleven (42.3\%) patients had two or more 159 comorbidities. Six of them were ex-smokers and three were active smokers. Demographic and 160 clinical features of patients COVID-19 positive were similar to those of sarcoidosis patients 161 COVID-19 negative (Table 1). The administration of hydroxychloroquine was not associated 162 with a decreased occurrence of symptomatic COVID-19 (given in 13.9\% of patients COVID16319 negative vs $11.5 \%$ of infected patients, $p=1$ ). The use of immunosuppressant was not 164 significantly associated with a higher risk of symptomatic COVID-19 (39.3\% in patients 165 COVID-19 negative vs 38.4\% in COVID-19 positive patients, $p=0.96$ ).

166 At the onset of COVID-19, patients infected were receiving ARBs/ACE inhibitors (23.1\%), 167 HMGCoa reductase inhibitors (15.4\%), corticosteroids [84.6\%, mean dose of 8.6(6) mg/day], 168 hydroxychloroquine (11.5\%), immunosuppressant (38.4\%), IL-6 inhibitors (7.7\%), and TNF 169 inhibitors (3.8\%). Main symptoms of COVID-19 in this cohort of sarcoidosis patients are 170 listed in Table 2. Specific treatments for COVID-19 consisted in lopinavir/ritonavir and 171 pristinamycin $(n=1)$, hydroxychloroquine $(n=2)$, azithromycin $(n=1)$ and withdrawal of 172 immunosuppressant $(\mathrm{n}=2)$.

173 COVID-19 positive sarcoidosis patients requiring hospitalization 
174 Among the 26 patients with COVID-19, four (15.4\%) required admission to hospital 175 [medicine ward $(n=2)$ and intensive care unit $(n=2)$ ], one required mechanical ventilation, one 176 high flow nasal cannula and two died. One woman (73 years) with sarcoidosis associated with 177 Takayasu arteritis died at the emergency room because of acute respiratory insufficiency. One 178 man (49 years) with stage 4 pulmonary sarcoidosis, diabetes and history of pulmonary 179 embolism, was admitted to hospital 10 days after COVID-19 onset. He did not receive 180 specific treatments for COVID-19. He required mechanical ventilation and died 20 days after 181 hospital admission.

182 All patients requiring admission to hospital [50\% of male gender, mean age of 61(11.5) years]

183

184

185

186

187

188

189

190

191

192

193

194

195

196

197

198

199

200

201

202

203

204 presented pulmonary sarcoidosis (stage II/III for two and stage IV for one), two of them had cardiac sarcoidosis and none had neurological sarcoidosis. All of them had at least one comorbidity [hypertension $(n=1)$, diabetes $(n=2)$, coronary artery disease $(n=1)$, Takayasu $(n=1)$, heart failure $(n=1)$, and overweight $(n=4)]$. Three $(75 \%)$ of them had two or more comorbidities. None of them was an active smoker. At the onset of COVID-19, three patients were receiving corticosteroids [mean dose of 12.3 (7-20) $\mathrm{mg} /$ day], one mycophenolate mofetil and one leflunomide. None was receiving hydroxychloroquine.

\section{Discussion}

To our knowledge, this study is the first report on the prevalence, clinical presentation and outcome of COVID-19 in patients with sarcoidosis. The prevalence of infected patients (13\%) in our cohort of sarcoidosis patients does seem significantly different to that estimated COVID-19 prevalence in Ile de France (9.9\%) and Grand-Est (9.3\%), both regions being the most affected by the pandemic in France (6). Our results are consistent with previous data on cohort of patients with other inflammatory and autoimmune disorders (4).

The rate of infected patients with severe symptoms requiring hospitalization reached $15 \%$, which is about four times higher than the rate of hospitalizations in the general population in France, estimated at respectively $3.6 \%$ and $3.5 \%$ (2.1 - 5.4) for all the French population and patients aged 50 to 59 years-old, the age group corresponding to the median age of sarcoidosis patients in our cohort (6). In the same line, the rate of death is $7.7 \%$ in our cohort. However, this should be considered with caution given the small number of patients concerned although this mortality rate seems to be higher than that estimated in the population aged from 50 to 59 years old in France (than 1\%) (6). This mortality rate may be explained by the high prevalence of comorbidities in sarcoidosis patients, as 92\% COVID-19 positive sarcoidosis patients in our cohort had one or more comorbidities. The rate of diabetes in our cohort is two 
208 to three times higher than that of the general population ( $<10 \%$ before 60 years in France) (8).

209 The prevalence of diabetic patients in our sarcoidosis cohort reached $23 \%$ for patients with 210 COVID-19 and 50\% for hospitalized patients, compared to $6 \%$ and $14 \%$ respectively in a 211 New York series reporting patients with an immune-mediated inflammatory disease COVID21219 positive (9). The body mass index of sarcoidosis patients is also particularly high (10). 213 Indeed, diabetes, hypertension and obesity are risk factors known to be associated with poor 214 prognosis in COVID-19 positive patients, increasing the rate of hospitalizations and mortality 215 (11 - 15). The mortality rate in diabetic COVID-19 positive patients was reported to reach $2167.8 \%$ (16) and 30\% in hospitalized patients, which is quite similar to the mortality rate found 217 in our cohort. Consistently, all hospitalized patients in the present study have at least one 218 comorbidity. It should be noted that one of the two dead patients had severe cardiovascular 219 comorbidities, and that the second had stage four sarcoidosis pulmonary involvement (17).

220 In our cohort, the high rate of patients with metabolic syndrome can partly be explained by a 221 high rate of systemic corticosteroid therapy, i.e. 85\% of COVID-19 patients and 75\% of 222 hospitalized patients compared to $9 \%$ and $29 \%$ respectively in the study by Haberman et al 223 (18). Our results are consistent with those of previous studies showing that the use of systemic corticosteroids is a risk factor for a severe course of COVID-19, particularly in inflammatory bowel diseases (19). None of the hospitalized patients was a daily smoker or ex-smoker,

226 which is consistent with several studies finding a low proportion of smokers among patients 227 with a moderate to severe outcome. However, the relationship between smoking and COVID22819 outcome is controversial, with multiple conflicting reports in the current literature $(15,20)$.

\section{Conclusion}

231 In conclusion, the rate of COVID-19 infections among patients with sarcoidosis appears to be 232 very slightly higher to that of the general population. The rates of hospitalization and 233 mortality appeared to be higher than in the general population. 


\section{References}

237 1. Llanos O, Hamzeh N. Sarcoidosis. Med Clin North Am. 2019 May;103(3):527-34.

2. Alijotas-Reig J, Esteve-Valverde E, Belizna C, Selva-O'Callaghan A, Pardos-Gea J,

239 Quintana A, et al. Immunomodulatory therapy for the management of severe COVID-19.

240 Beyond the anti-viral therapy: A comprehensive review. Autoimmun Rev. 2020 $241 \quad$ Jul;19(7):102569.

242 3. Toniati P, Piva S, Cattalini M, Garrafa E, Regola F, Castelli F, et al. Tocilizumab for the 243 treatment of severe COVID-19 pneumonia with hyperinflammatory syndrome and acute 244 respiratory failure: A single center study of 100 patients in Brescia, Italy. Autoimmun Rev. $2452020 \mathrm{Jul} ; 19(7): 102568$.

246 4. D’Silva KM, Serling-Boyd N, Wallwork R, Hsu T, Fu X, Gravallese EM, et al. Clinical 247 characteristics and outcomes of patients with coronavirus disease 2019 (COVID-19) and 248 rheumatic disease: a comparative cohort study from a US "hot spot." Ann Rheum Dis. 2020 249 May 26

250 5. Hunninghake GW, Costabel U, Ando M, Baughman R, Cordier JF, du Bois R, et al. 251 ATS/ERS/WASOG statement on sarcoidosis. American Thoracic Society/European 252 Respiratory Society/World Association of Sarcoidosis and other Granulomatous Disorders. 253 Sarcoidosis Vasc Diffuse Lung Dis. 1999 Sep;16(2):149-73.

254 6. Salje H, Tran Kiem C, Lefrancq N, Courtejoie N, Bosetti P, Paireau J, et al. Estimating the 255 burden of SARS-CoV-2 in France. Science. 2020 May 13.

256 7. Boulware DR, Pullen MF, Bangdiwala AS, Pastick KA, Lofgren SM, Okafor EC, et al. A 257 Randomized Trial of Hydroxychloroquine as Postexposure Prophylaxis for Covid-19. N Engl 258 J Med. 2020 Jun 3.

259 8. Santé Publique France: Diabète: https://www.santepubliquefrance.fr/maladies-et260 traumatismes/diabete.

261 9. Haberman R, Axelrad J, Chen A, Castillo R, Yan D, Izmirly P, et al. Covid-19 in Immune262 Mediated Inflammatory Diseases - Case Series from New York. N Engl J Med. 2020 Apr 29.

263 10. Organisation de coopération et de développement économiques (OCDE) : Population en 264 surpoids ou obèse : https://www.oecd-ilibrary.org/social-issues-migration-health/overweight265 or-obese-population/indicator/french_debbeb4b-fr

266 11. Wang D, Hu B, Hu C, Zhu F, Liu X, Zhang J, et al. Clinical Characteristics of 138 267 Hospitalized Patients With 2019 Novel Coronavirus-Infected Pneumonia in Wuhan, China. 268 JAMA. 2020 Feb 7. 
12. Zhou F, Yu T, Du R, Fan G, Liu Y, Liu Z, et al. Clinical course and risk factors for mortality of adult inpatients with COVID-19 in Wuhan, China: a retrospective cohort study. Lancet. 2020 28;395(10229):1054-62.

272 13. Grasselli G, Zangrillo A, Zanella A, Antonelli M, Cabrini L, Castelli A, et al. Baseline 273 Characteristics and Outcomes of 1591 Patients Infected With SARS-CoV-2 Admitted to ICUs 274 of the Lombardy Region, Italy. JAMA. 202006.

275 14. Buckner FS, McCulloch DJ, Atluri V, Blain M, McGuffin SA, Nalla AK, et al. Clinical 276 Features and Outcomes of 105 Hospitalized patients with COVID-19 in Seattle, Washington. 277 Clin Infect Dis. 2020 May 22.

278 15. Richardson S, Hirsch JS, Narasimhan M, Crawford JM, McGinn T, Davidson KW, et al. 279 Presenting Characteristics, Comorbidities, and Outcomes Among 5700 Patients Hospitalized 280 With COVID-19 in the New York City Area. JAMA. 2020 Apr 22.

281 16. Zhu L, She Z-G, Cheng X, Qin J-J, Zhang X-J, Cai J, et al. Association of Blood Glucose 282 Control and Outcomes in Patients with COVID-19 and Pre-existing Type 2 Diabetes. Cell 283 Metab. 2020 02;31(6):1068-1077.e3.

284 17. Song JW, Hong S-B, Lim C-M, Koh Y, Kim DS. Acute exacerbation of idiopathic 285 pulmonary fibrosis: incidence, risk factors and outcome. Eur Respir J. 2011 Feb;37(2):35628663.

287 18. Haberman R, Axelrad J, Chen A, Castillo R, Yan D, Izmirly P, et al. Covid-19 in 288 Immune-Mediated Inflammatory Diseases - Case Series from New York. N Engl J Med. 2020 289 Apr 29.

290 19. Brenner EJ, Ungaro RC, Gearry RB, Kaplan GG, Kissous-Hunt M, Lewis JD, et al. 291 Corticosteroids, but not TNF Antagonists, are Associated with Adverse COVID-19 Outcomes 292 in Patients With Inflammatory Bowel Diseases: Results from an International Registry. 293 Gastroenterology. 2020 May 18.

294 20. Chakladar J, Shende N, Li WT, Rajasekaran M, Chang EY, Ongkeko WM. Smoking295 Mediated Upregulation of the Androgen Pathway Leads to Increased SARS-CoV-2 296 Susceptibility. Int J Mol Sci. 2020 May 21;21(10). 
303

304

305

306

307

308

309

310

311

312

313

314

315

316

317

318 
Table 1: Clinical characteristics of sarcoidosis patients without and with COVID-19

\begin{tabular}{|c|c|c|c|}
\hline & $\begin{array}{c}\text { Patients without } \\
\text { COVID-19 } \\
(n=173)\end{array}$ & $\begin{array}{c}\text { Patients with } \\
\text { COVID-19 } \\
(n=26)\end{array}$ & $p$ \\
\hline \multicolumn{4}{|l|}{ Clinical features } \\
\hline Age (mean, SD) & $53.2(14.1)$ & $50.3(13.6)$ & 0.32 \\
\hline Male gender, $\mathrm{n}(\%)$ & $73(42.2)$ & $13(50)$ & 0.64 \\
\hline \multicolumn{4}{|l|}{ Involvements of sarcoidosis } \\
\hline Lung involvement, $\mathrm{n}(\%)$ & $124(71.7)$ & $19(73)$ & 0.95 \\
\hline $\begin{array}{l}\text { Stage of pulmonary involvement II/III, } \\
\mathrm{n}(\%)\end{array}$ & $73(42.2)$ & $14(60.8)$ & 0.5 \\
\hline Stage of pulmonary involvement IV, $\mathrm{n}(\%)$ & $5(2.9)$ & $1(3.8)$ & 0.58 \\
\hline Vital capacity (\%), mean (SD) & $79.2(38)$ & $80.9(37)$ & \\
\hline Total lung capacity (\%), mean (SD) & 77.3(33.4) & $76.8(33.2)$ & \\
\hline $\begin{array}{l}\text { Diffusing capacity for carbon monoxide } \\
(\%) \text {, mean (SD) }\end{array}$ & $64.5(31.2)$ & 69.3(29.3) & \\
\hline Lymph nodes, $\mathrm{n}(\%)$ & $80(46.2)$ & $13(50)$ & 0.83 \\
\hline Cardiac, $\mathrm{n}(\%)$ & $30(17.3)$ & $4(15.4)$ & 1 \\
\hline Neurological, n(\%) & $63(36.4)$ & $6(23.1)$ & 0.39 \\
\hline Ophthalmological, $\mathrm{n}(\%)$ & $67(38.7)$ & $12(46.2)$ & 0.61 \\
\hline \multicolumn{4}{|l|}{ Other comorbidities } \\
\hline One or more other comorbidity, $\mathrm{n}(\%)$ & $136(78.6)$ & $24(92)$ & 0.6 \\
\hline Hypertension, $\mathrm{n}(\%)$ & $53(30.6)$ & $7(26.9)$ & 0.8 \\
\hline Diabetes, $\mathrm{n}(\%)$ & $36(20.8)$ & $6(23.1)$ & 0.83 \\
\hline Cardiac failure, $\mathrm{n}(\%)$ & $8(4.6)$ & $2(7.7)$ & 0.63 \\
\hline $\begin{array}{l}\text { Chronic respiratory disease (chronic } \\
\text { obstructive lung disease or asthma), } \mathrm{n}(\%)\end{array}$ & $22(12.7)$ & $5(19)$ & 0.39 \\
\hline Malignant tumor, $\mathrm{n}(\%)$ & $27(15.6)$ & $1(3.8)$ & 0.21 \\
\hline Body Mass Index (mean, SD), n(\%) & $27.6(7)$ & $27.1(4.8)$ & 0.85 \\
\hline \multicolumn{4}{|l|}{ Smoking habits } \\
\hline Ex-Smoker, n(\%) & $40(23.1)$ & $6(23.1)$ & 0.99 \\
\hline Daily smoker, $\mathrm{n}(\%)$ & $19(11)$ & $3(11.5)$ & 1 \\
\hline \multicolumn{4}{|l|}{ Treatments } \\
\hline NSAID, $\mathrm{n}(\%)$ & $10(5.8)$ & $2(7.7)$ & 0.66 \\
\hline ACE inhibitors or ARBs, $\mathrm{n}(\%)$ & $39(22.5)$ & $6(23.1)$ & 0.96 \\
\hline HMGCoa reductase inhibitors, $\mathrm{n}(\%)$ & $29(16.8)$ & $4(15.4)$ & 1 \\
\hline Hydroxychloroquine, $\mathrm{n}(\%)$ & $24(13.9)$ & $3(11.5)$ & 1 \\
\hline Corticosteroids, $\mathrm{n}(\%)$ & $117(67.6)$ & $22(84.6)$ & 0.47 \\
\hline Corticosteroids dosage, mg/day mean(SD) & $6.7(3.4)$ & $8.6(6)$ & 0.29 \\
\hline Immunosuppressants, $\mathrm{n}(\%)$ & $68(39.3)$ & $10(38.4)$ & 0.96 \\
\hline Methotrexate, n(\%) & $38(22)$ & $4(15.4)$ & 0.62 \\
\hline Mycophenolate mofetil, $\mathrm{n}(\%)$ & $23(13.3)$ & $3(11.5)$ & 1 \\
\hline Azathioprin, $\mathrm{n}(\%)$ & $2(1.2)$ & $1(3.8)$ & 0.35 \\
\hline TNF inhibitors, $\mathrm{n}(\%)$ & $11(6.4)$ & $1(3.8)$ & 1 \\
\hline IL-6 inhibitors, $\mathrm{n}(\%)$ & $2(1.2)$ & $2(7.7)$ & 0.09 \\
\hline
\end{tabular}


320 ACE: angiotensin-converting enzyme, ARB: angiotensin II receptor blocker, COVID-19: 321 Coronavirus disease 2019, IL6: interleukin 6, NSAID: nonsteroidal anti-inflammatory drug, 322 SD: standard deviation, TNF: tumor necrosis factor 
Table 2: Clinical characteristics and outcome of COVID-19 in sarcoidosis patients

\begin{tabular}{|c|c|}
\hline & $\begin{array}{c}\text { Patients with } \\
\text { COVID-19 }(n=27)\end{array}$ \\
\hline \multicolumn{2}{|l|}{ Symptoms of COVID-19 } \\
\hline Asthenia, $\mathrm{n}(\%)$ & $16(61.6)$ \\
\hline Fever, $\mathrm{n}(\%)$ & $18(69.3)$ \\
\hline Cough, n(\%) & $19(73.1)$ \\
\hline Rhinorrhea, $\mathrm{n}(\%)$ & $10(38.5)$ \\
\hline Anosmia, $\mathrm{n}(\%)$ & $5(19.2)$ \\
\hline Dysgeusia, n(\%) & $7(26.9)$ \\
\hline Headaches, $\mathrm{n}(\%)$ & $17(65.4)$ \\
\hline Myalgia, $\mathrm{n}(\%)$ & $14(53.8)$ \\
\hline Shortness of breath, $\mathrm{n}(\%)$ & $12(46.2)$ \\
\hline Chest pain, n(\%) & $8(30.8)$ \\
\hline Diarrhea, $\mathrm{n}(\%)$ & $6(23.1)$ \\
\hline Cutaneous lesions, $\mathrm{n}(\%)$ & $4(15.4)$ \\
\hline Duration of symptoms, mean (SD) days & $16.6(13.8)$ \\
\hline \multicolumn{2}{|l|}{$\begin{array}{l}\text { Chest findings: extension of ground-glass } \\
\text { opacities and/or consolidation }\end{array}$} \\
\hline$<10 \%$ & $1(25 \%)$ \\
\hline $10-25 \%$ & $1(25 \%)$ \\
\hline $25-50 \%$ & $2(50 \%)$ \\
\hline \multicolumn{2}{|l|}{ Treatments } \\
\hline Hydroxychloroquine, $\mathrm{n}(\%)$ & $2(7.7)$ \\
\hline Antibiotic therapy, $\mathrm{n}(\%)$ & $2(7.7)$ \\
\hline Antiviral therapy, $\mathrm{n}(\%)$ & $1(3.8)$ \\
\hline Tocilizumab, $\mathrm{n}(\%)$ & $0(0)$ \\
\hline Increase or initiation of corticosteroids, $\mathrm{n}(\%)$ & $0(0)$ \\
\hline $\begin{array}{l}\text { Withdrawal or decrease of immunosuppressants, } \\
\mathrm{n}(\%)\end{array}$ & $2(7.7)$ \\
\hline \multicolumn{2}{|l|}{ Outcomes } \\
\hline Admission to hospital, $\mathrm{n}(\%)$ & $4(15.4)$ \\
\hline Admission to Intensive care, $\mathrm{n}(\%)$ & $2(7.7)$ \\
\hline Invasive ventilation, $\mathrm{n}(\%)$ & $1(3.8)$ \\
\hline Oxygen therapy, n(\%) & $2(7.7)$ \\
\hline High flow nasal cannula, $\mathrm{n}(\%)$ & $1(3.8)$ \\
\hline $\mathrm{ECMO}, \mathrm{n}(\%)$ & $0(0)$ \\
\hline Death, $\mathrm{n}(\%)$ & $2(7.7)$ \\
\hline Discharged, $\mathrm{n}(\%)$ & $2(7.7)$ \\
\hline
\end{tabular}

325 COVID-19: Coronavirus disease 2019, ECMO: extracorporeal membrane oxygenation, SD: standard deviation. 